\title{
Tissue content of sulfomucins and sialomucins in the colonic mucosa, without fecal stream, undergoing daily intervention with sucralfate ${ }^{1}$
}

\author{
Christiny Emmanuelle Gabriel Bonassa', José Aires Pereira' ${ }^{\text {II }}$ Fábio Guilherme Caserta Maryssael de Campos ${ }^{\text {III }}$, Murilo Rocha \\ Rodrigues $^{\mathrm{IV}}$, Daniela Tiemi Sato ${ }^{\mathrm{IV}}$, Felipe David Mendonça Chaim ${ }^{\mathrm{I}}$, Carlos Augusto Real Martinez \\ DOI: http://dx.doi.org/10.1590/S0102-865020150050000004 \\ IFellow Master degree, Postgraduate Program in Health Sciences, Sao Francisco University (USF), Bragança Paulista-SP, Brazil. Acquisition and \\ interpretation of data, histological examinations, technical procedures. \\ IIAssistant Professor, Discipline of Pathology, School of Medicine, USF, Bragança Paulista-SP, Brazil. Acquisition and interpretation of data, histological \\ and histochemical analysis.

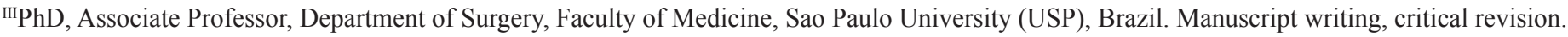

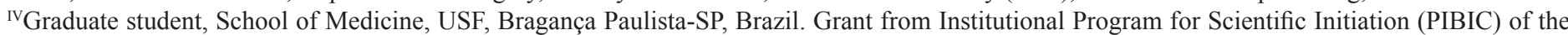 \\ National Council of Scientific and Technological Development (CNPq), Ministry of Science, Technology and Inovation, Brazil. Acquisition of data, \\ histological examinations, technical procedures. \\ ${ }^{v} \mathrm{PhD}$, Associate Professor, Postgraduate Program in Health Sciences, USF, Bragança Paulista-SP. Associate Professor, Department of Surgery, \\ Campinas State University (UNICAMP), Brazil. Intellectual and scientific content of the study, manuscript writing, critical revision.
}

\begin{abstract}
PURPOSE: To measure the content of acidic mucin, sialomucin, and sulfomucins in the colonic mucosa without fecal stream submit to intervention with sucralfate (SCF).

METHODS: Thirty-six rats were submitted to a right colostomy and a distal mucous fistula and divided into two groups according to sacrifice to be performed two or four weeks. Each group was divided into three subgroups according daily application of enemas containing saline, SCF at $1.0 \mathrm{~g} / \mathrm{kg} / \mathrm{day}$ or $2.0 \mathrm{~g} / \mathrm{kg} / \mathrm{day}$. Colitis was diagnosed by histological analysis. Acid mucins were determined with the Alcian-Blue and sulfomucin and sialomucin by high iron diamine-alcian blue (HID-AB) techniques. The mucins were quantified by computer-assisted image analysis. Mann-Whitney and ANOVA tests were used to analyze the results establishing the level of significance of $5 \%$ for both $(\mathrm{p}<0.05)$.

RESULTS: SCF enemas decreased the inflammation score and was related to the concentration used and time of the intervention. SCF at both concentrations increased the content of acid mucin, which was related to the concentration used and to the improvement in the inflammatory score. There was an increase in the content of sulfomucins and sialomucins in SCF groups. SCF increased sulfomucins from 2 weeks of intervention, which was not related to the dose or time of application. The increase in sialomucin content was related to the time and dose used in the intervention.
\end{abstract}

CONCLUSION: Sucralfate increased the content of acidic mucins, primarily at the expense of sialomucin, which was affected by the dose and time of intervention.

Key words: Colon. Colitis. Mucins. Sialomucins. Sucralfate. Image Processing, Computer-Assisted. Rats. 


\section{Introduction}

The colon mucosa is considered the most perfect human barrier: it protects humans against invading bacteria, antigens and existing toxins from the intestinal lumen ${ }^{1}$. A thin layer of mucus overlying the colonic epithelium constitutes the first line of defense, and most of its protective effect is due to the presence of mucins, which predominantly consist of glycoproteins ${ }^{2,3}$. Epithelial cells produce two types of mucins, neutral and acid ${ }^{4,5}$. Acidic mucin, in turn, consist of two subtypes, according to the predominance of sulfate radicals (sulfomucins) or sialic acid (sialomucin) ${ }^{2,6}$. In the normal colonic mucosa, the ratio of acidic to neutral mucins remains constant throughout the digestive tract, but it may be modified in various inflammatory bowel diseases (IBDs) ${ }^{2,7}$.

Previous studies have shown that the capacity of the epithelium of the large intestine to produce mucins depends on an adequate supply of short-chain fatty acids (SCFAs) formed by the fermentation of the fiber ingested in the $\operatorname{diet}^{4-6}$. SCFAs, particularly butyric acid, are essential for mucous cells to express genes related to the transcription of the protein fraction of mucin $^{3,8}$. The diversion of the fecal stream, which prevents the supply of ACGG to the excluded colon, reduces the ability of the goblet cells to produce mucins and tends to worsen with time exclusion $^{5,6}$. Experimental studies using an experimental model of diversion colitis (DC) have shown that in colonic mucosa without fecal stream, there is a reduction in the level of total acidic mucins, primarily at the expense of sialomucins ${ }^{5,6}$. The reduction in the tissue content of acidic mucins was related to the inflammatory process in the mucosa of the colon devoid of the supply of SCFAs ${ }^{5,6}$. These studies suggest that in colon segments devoid of SCFAs, there are changes in the energy metabolism that lead to the increased production of reactive oxygen species (ROS). The resulting oxidative stress damages the layer of mucus that covers the colonic epithelium, modifying different types of mucins ${ }^{5,6,9}$.

The application of enemas containing natural or synthetic substances, with antioxidant effects or rich SCFA solutions, improves tissue inflammatory changes detected in the DC model ${ }^{10-14}$. Conversely, the exposure of the colonic mucosa to substances with great oxidant power, such as hydrogen peroxide $\left(\mathrm{H}_{2} \mathrm{O}_{2}\right)$, worsens the epithelial damage ${ }^{15}$. This evidence suggests that it would be interesting to evaluate the effect of substances with antioxidant effects in protecting the mucin layer to promote the recovery of the colonic epithelium.

Sucralfate (SCF) is the salt formed by disaccharide sucrose octosufalto associated with polyaluminum hydroxide ${ }^{16}$. The substance is considered a cytoprotective complex that was initially used to prevent or treat diseases of the upper digestive tract ${ }^{17}$. The therapeutic effects of SCF mucosal skin lesions are related to the property that the formed complex must cling firmly to the bloody surface of epithelial lesions. However, it has recently been shown that the SCF has other functional properties, such as stimulating mucus production and increasing the production of prostaglandins (PGE2) and epidermal growth factor (EGF) $)^{18}$. A study also showed that the administration of SCF can stimulate the formation of acid in the upper digestive tract mucins ${ }^{19}$. The topical application of SCF also showed antioxidant activity in reducing the formation of ROS produced by neutrophils present in inflamed tissue ${ }^{20}$. Kochhar et $a .^{21}$, were the first authors to demonstrate the effectiveness of the application of enemas containing SCF in controlling rectal bleeding that is caused by radiation proctitis (RP). Since then, a number of studies have confirmed the effects of SCF on clinical, endoscopic and histological improvement in patients with RP, and it is now used to treat other IBDs that evolve with the formation of epithelial ulcers ${ }^{22-27}$. Despite the DC course with reduced mucin content in the glands of the colonic epithelium and the formation of epithelial ulceration related to tissue oxidative stress, to the best of our knowledge, the effects of SCF in the production of acid mucins and its subtypes, sulfomucins and sialomucins, have not yet been evaluated in patients or experimental models of $\mathrm{DC}^{5,6,9}$. Therefore, the objective of this study is to determine, in an experimental model of DC, the effects of daily enemas with SCF on the levels of acidic mucin, sialomucin and sulfomucins in the colonic mucosa in the absence of a fecal stream.

\section{Methods}

The experiments were performed in accordance with the principles outlined by Federal Law n 11.794 (10/08/2008)), and approved by the Ethics Committee in Animal Research of São Francisco University ( $\left.\mathrm{N}^{\circ} 2211 / 2007\right)$.

Thirty-six male, SPF, Wistar rats (300-350g) were obtained from the São Francisco University School of Medicine barrier facility and maintained on light/dark cycles of 12 hours; they were fed a standard rodent chow diet. They were deprived of food, but not water, for $24 \mathrm{~h}$ prior to the surgical procedure.

\section{Surgical technique}

The diversion of the fecal stream was performed in all animals under general anesthesia by the intramuscular administration of $0.1 \mathrm{ml} / 100 \mathrm{~g}$ of a $1: 1(\mathrm{v} / \mathrm{v})$ solution of ketamine $(50 \mathrm{mg} / \mathrm{ml})$ and xylazine $(20 \mathrm{mg} / \mathrm{ml})$. The abdomen 
was shaved, and a 3-cm-long midline incision was made. The left colon was exteriorized and sectioned in its mid-portion, corresponding to the descending colon, approximately $3 \mathrm{~cm}$ above the Peyer's lymphoid patch, which is located in the rectalsigmoid transition. Two circular skin pellets, $3 \mathrm{~mm}$ in diameter and $3 \mathrm{~cm}$ apart, were made in the left side of the abdominal wall at the same vertical level. The proximal end of the colon was exteriorized through the cranial cutaneous orifice, and the distal stoma was exteriorized through the caudal skin opening after splitting the abdominal wall muscles. The proximal end and distal stoma were fixed to the skin with full-thickness sutures. Before the fixation of the distal stoma to the skin, the distal colon was cleaned with the infusion of a physiologic solution until the fecal contents were completely removed. The abdominal incision was closed in two stages (aponeurosis and the skin). In this way, two colostomies were performed; one proximal colostomy was performed as a terminal colostomy with intestinal transit, and the second colostomy was performed as a distal stoma devoid of the fecal stream. Rats were maintained in individual cages, and no particular care was taken with respect to the stomas and abdominal incisions.

\section{Experimental groups}

The animals were divided into two experimental groups with 18 animals each, according to whether they were euthanized after two or four weeks. Each experimental group was divided into six subgroups $(n=6)$ according to the intervention solution employed and the time of intervention. In the first and second subgroups, 12 animals received daily rectal enemas consisting of $40 \mathrm{ml}$ of $0.9 \%$ saline solution (control subgroup) at $37^{\circ} \mathrm{C}$ for two weeks $(n=6)$ and four weeks $(n=6)$. In the second subgroup, 12 animals received daily rectal enemas consisting of $40 \mathrm{ml}$ of SCF (Sigma-Aldrich, St Louis, MO, USA) at a concentration of $1.0 \mathrm{~g} /$ $\mathrm{kg}$ for two weeks $(\mathrm{n}=6)$ and four weeks $(\mathrm{n}=6)$. Finally, 12 animals of the third subgroup received daily enemas consisting of $40 \mathrm{ml}$ of $\mathrm{SCF}$ at a concentration of $2.0 \mathrm{~g} / \mathrm{kg}$ for two weeks $(\mathrm{n}=6)$ and four weeks $(n=6)$. To standardize the speed and time of application, the enemas were administered in all animals with an infusion pump, whose speed was standardized at $2 \mathrm{ml} / \mathrm{min}$.

\section{Sample collection}

Upon completion of the pre-determined irrigation period, the animals were anesthetized as described above, and the midline incision was opened again. In both groups, specimens were collected from the intra-abdominal part of the excluded region (colon without fecal stream) subjected to irrigation with the proposed substances. The removed specimen, measuring approximately $4.0 \mathrm{~cm}$, was longitudinally opened through the anti-mesenteric border fixed in a piece of cork and subjected to histological and histochemical analysis

\section{Histological and histochemical analysis}

Fragments prepared for histological analysis were immersed in 10\% neutral formalin buffer (Sigma-Aldrich, St. Louis, MO, USA) for $24 \mathrm{~h}$, dehydrated by exposure to increasing ethanol concentrations, and embedded in paraffin. Thereafter, sections of tissue were cut at $5 \mu \mathrm{m}$ on a rotary microtome (Leica Biosystems, Nussloch, Germany), mounted on a glass slide, cleared, hydrated and stained with hematoxylin-eosin (HE) to evaluate them for the presence of colitis. Slide analysis was performed using an optical microscope (Eclipse DS-50, Nikon Inc., Osaka, Japan) with a final magnification of $200 \times$. Photomicrographs were collected with a digital video-capture camera (DS-Fi-50; Nikon Inc., Osaka, Japan) coupled to the microscope body and digitized by a computer system of image analysis (NIS-Elements; Nikon Inc., Osaka, Japan). The diagnosis of colitis was made based on the presence of the following three independent histological parameters: reduction of the crypt length, neutrophil infiltration of the mucosa and epithelial loss. These variables were stratified as crosses, according to the degree of each, as follows: a) + absent or no alterations; b) ++ when intensity was mild d) +++ moderate and e) ++++ intense. For all analyzed variables, the final value considered for each animal was the mean value after quantification of three distinct histological fields.

The tissue expression of the acid mucins was determined individually by means of the Alcian Blue (AB) histochemical technique. The total acid mucin content stained blue $^{6}$. To identify the subtypes of acid mucins (sulfomucins and sialomucins), the slides were stained using the high iron diamine-alcian blue (HID-AB) histochemical technique in accordance with the standardized methodology ${ }^{6}$. In summary, the slides were deparaffinized in two successive xylol baths for 10 minutes, treated with an alcohol rinse in three successive baths of pure alcohol and then hydrated in running water for five minutes. After this step, they were washed in three successive baths of distilled water and then exposed to high-iron diamine (HID) for six hours. The HID solution consisted of $120 \mathrm{mg}$ de NN-dimethyl-meta-phenylenediamine-dihydrochloride, $20 \mathrm{mg}$ de NN-dimethyl-paraphenylenediamine-dihydrochloride, $50 \mathrm{ml}$ 
of distilled water and $1.4 \mathrm{ml}$ of a recently prepared solution of $60 \%$ ferric chloride. At the end of the HD staining, the sections were washed in running water for five minutes and then in three successive baths of distilled water. Subsequently, they were exposed to the staining agent alcian blue $(\mathrm{AB})$ for 10 minutes and then washed in running water for five minutes followed by three successive baths of distilled water. The $1 \% \mathrm{AB}$ staining medium was prepared in acetic acid ( $\mathrm{pH} 2.5)$. At the end of this step, the slides were counterstained with neutral red for eight minutes and washed again in running water. They were then dehydrated in three successive baths of pure alcohol and diaphanized in three baths of xylol, and cover slips were mounted using resin. Through the HID-AB technique, sulfomucins stained brown, and sialomucins stained blue. A pathologist with expertise in diseases of the digestive tract, who was unaware of the origin of the material and objectives of the study, evaluated the presence of colitis and the pattern of tissue expression.

\section{Image processing, computer-assisted}

The tissue content of acid mucins, sulfomucins and sialomucins was quantified by means of computer-assisted image processing and was always performed in a focal field in which there were at least three complete and contiguous colonic crypts, with a magnification of $\times 200$. The selected images were captured on a video camera that had been coupled to an optical microscope. These images were processed and analyzed using the NIS-Elements 3.1 software (Nikon Inc., Osaka, Japan), installed in a microcomputer. By means of colored histograms in the RGB system, the software determined the color intensity in the number of pixels in each selected field, and the final data were transformed into percentage expressions by analyzed fields (\%/fields). The final value measured for each slice was the mean of the values found from evaluating three different fields. The presence of sulfomucins and sialomucins was quantified in the same glands.

\section{Statistical analysis}

The statistical analysis on the results obtained with a significance level of $5 \%(\mathrm{p} \leq 0.05)$. The data from each colon segment analyzed in each experimental group were expressed as the mean value with the respective standard error and were analyzed using the Biostat for Windows statistical software (version 5.0). To compare the mucin content in the different groups, the MannWhitney test was used. To analyze the variance in the mucin expression between the different experimental groups, ANOVA was used with the Newman-Keuls post-test.

\section{Results}

Figure 1A shows that the obtained colon segment was irrigated with $0.9 \%$ saline solution for 4 weeks, and Figure $1 \mathrm{~B}$ shows a colon irrigated with SCF at a concentration of $2.0 \mathrm{~g} / \mathrm{kg} /$ day for the same period of time. The animals in the control group had obvious epithelial loss, formation of epithelial ulceration and breakdown in the alignment of colic glands, while in animals treated with $2.0 \mathrm{~g} / \mathrm{kg} /$ day SCF, the epithelial surfaces in preserved intestinal crypts are shown aligned, with a standard normal distribution and preservation of the population of goblet cells. It is possible to observe a thin layer of SCF coating the epithelial surface of the colon mucosa as an increase in the intensity of staining on the luminal portion of the epithelial cells.

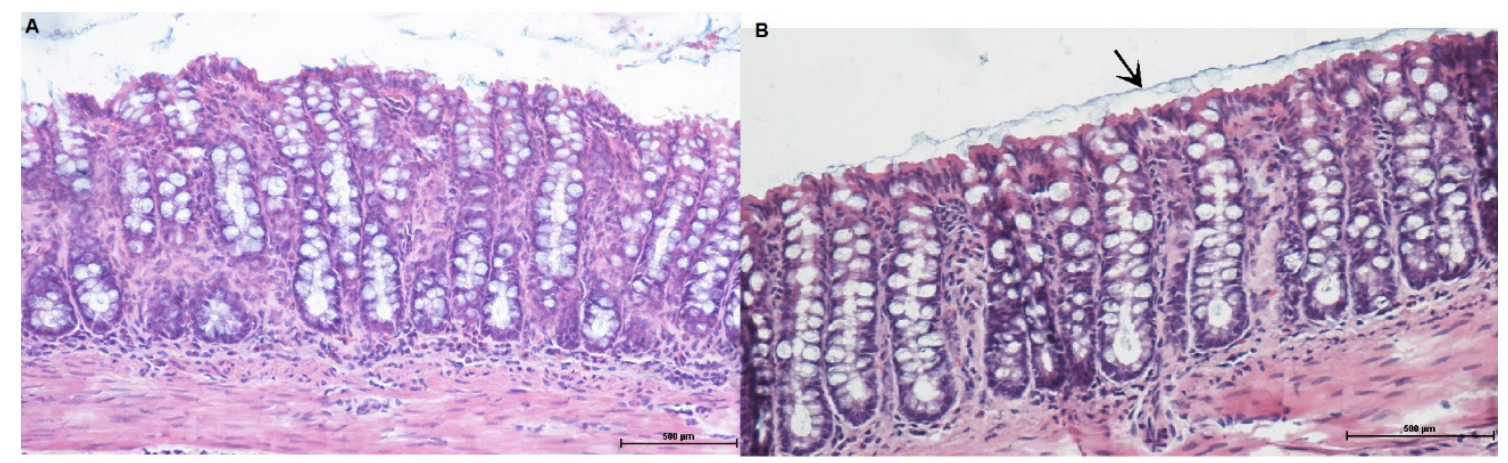

FIGURE 1 - A: colonic mucosa devoid of fecal stream after irrigation with $0.9 \%$ saline for four weeks (HE x100). B: colonic mucosa without fecal stream after irrigation with SCF at a concentration of $2.0 \mathrm{~g} / \mathrm{kg} /$ day for four weeks. SCF layer covering the mucosal surface (black arrow) (HE x200). 
Figure 2 A shows that the colon segment irrigated with $0.9 \%$ saline solution for four weeks, and Figure 2B shows a colon irrigated with SCF at a concentration of $2.0 \mathrm{~g} / \mathrm{kg} /$ day for the same period of time. The animals submitted to intervention with saline
(Figure 2A) have predominance of tissue expression of sulphomucins and absence of sialomucins. Differently, the animals underwent intervention with sucralfate have tissue expression of sialomucins mainly in the lower portions of the colon crypts (Figure 2B).

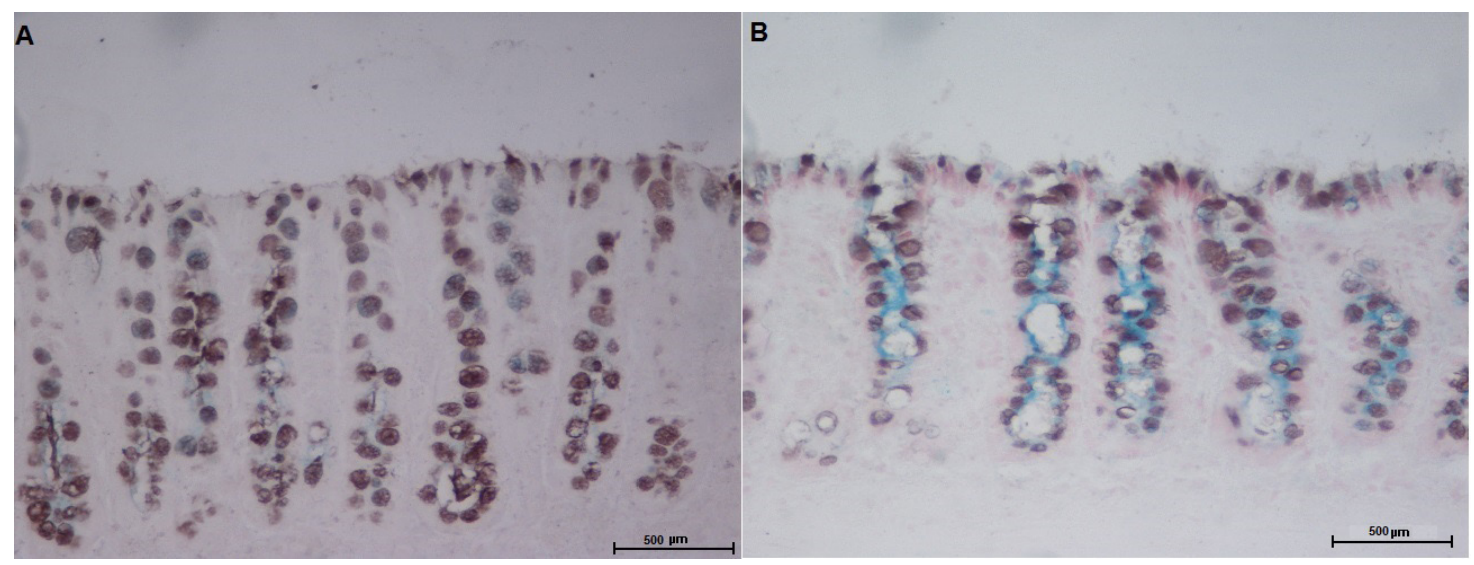

FIGURE 2 - A: colonic mucosa devoid of fecal stream after irrigation with $0.9 \%$ saline for four weeks with predominance of sulfomucins (HE x100). B: colonic mucosa without fecal stream after irrigation with SCF at a concentration of $2.0 \mathrm{~g} / \mathrm{kg} /$ day for four weeks with presence of sialomucins (HE x200).

Figure 3 shows the inflammatory scores found in colonic segments without a fecal stream two or four weeks after intervention with saline and $1.0 \mathrm{~g} / \mathrm{kg} /$ day and $2.0 \mathrm{~g} / \mathrm{kg} /$ day SCF. The results show that intervention with $\mathrm{SCF}$ at a concentration of
$2.0 \mathrm{~g} / \mathrm{kg} /$ day in colon segments devoid of the fecal stream reduces the colonic inflammation scores after four weeks of irrigation compared with the control group $(\mathrm{p}=0.03)$.

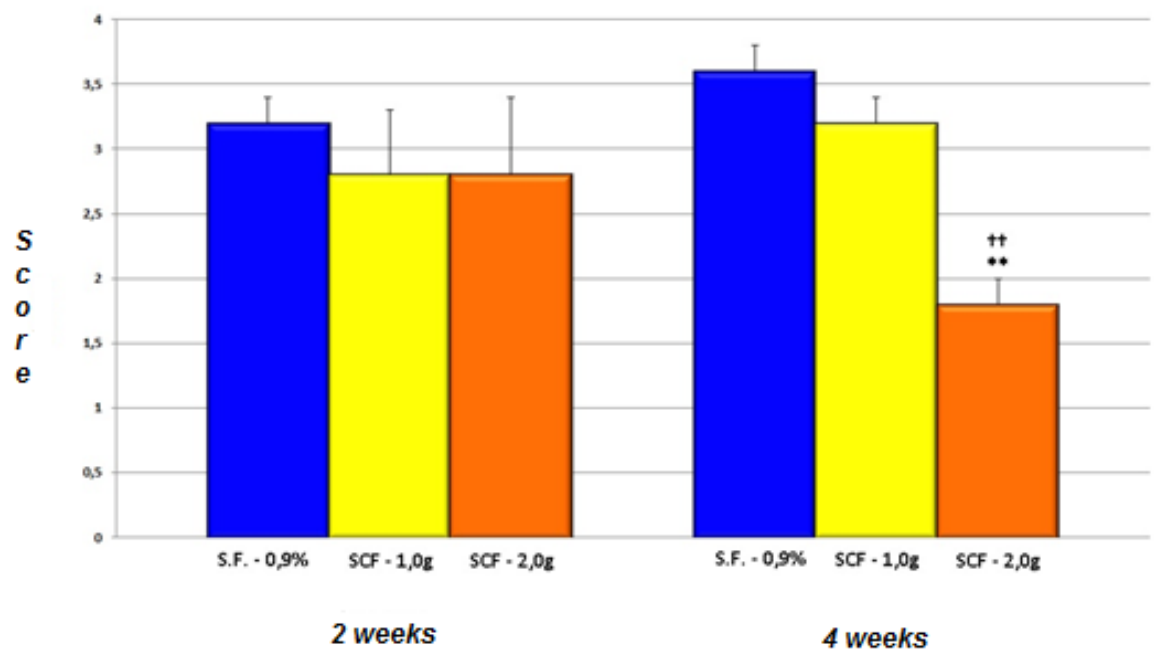

FIGURE 3 - Inflammatory score in the colon without fecal stream for the animals from the control (saline), SCF1 (SCF $1.0 \mathrm{~g} / \mathrm{kg} / \mathrm{day})$ and SCF2 (2.0 $\mathrm{g} / \mathrm{kg} /$ day) groups at two to four weeks. * = Significant (SCF2 $\times$ Control - four weeks). Mann-Whitney test.

Figure 4 shows the content of the total acid mucins found on the segments without fecal stream after intervention with saline and $1.0 \mathrm{~g} / \mathrm{kg} /$ day and $2.0 \mathrm{~g} / \mathrm{kg} /$ day SCF at two to four weeks. The results show that intervention with $\mathrm{SCF}$ at a concentration of 1.0 $\mathrm{g} / \mathrm{kg} /$ day or $2.0 \mathrm{~g} / \mathrm{kg} /$ day in the colon segments without a fecal stream significantly increased the content of total acidic mucins after two and four weeks of irrigation compared with the control group animals $(\mathrm{p}<0.01)$. 


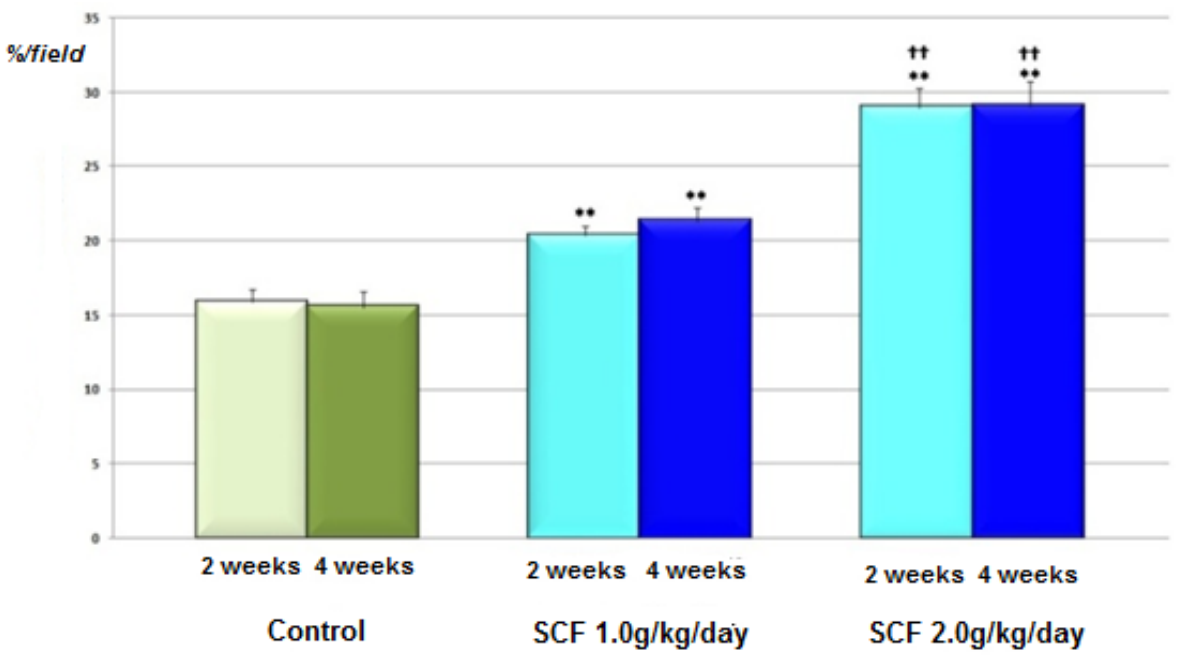

FIGURE 4 - Tissue content of acidic mucins in the control group animals SCF1 (SCF $1.0 \mathrm{~g} / \mathrm{kg} /$ day) and SCF2 (2.0 g/kg/day) groups, which were subjected to daily intervention with SCF for 2 and 4 weeks. ${ }^{* *}=\mathrm{p}<0.01$ (SCF1 $\times$ Control; SCF2 $\times$ Control); $\dagger \dagger=\mathrm{p}<0.01(\mathrm{SCF} 1 \times \mathrm{SCF} 2)$. MannWhitney test.

Figure 5 shows the contents of the sulfomucins found in colon segments without fecal stream after intervention with saline and $1.0 \mathrm{~g} / \mathrm{kg} /$ day and $2.0 \mathrm{~g} / \mathrm{kg} /$ day SCF for two to four weeks. The results show that intervention with SCF at a concentration of $\quad(p<0.01)$.

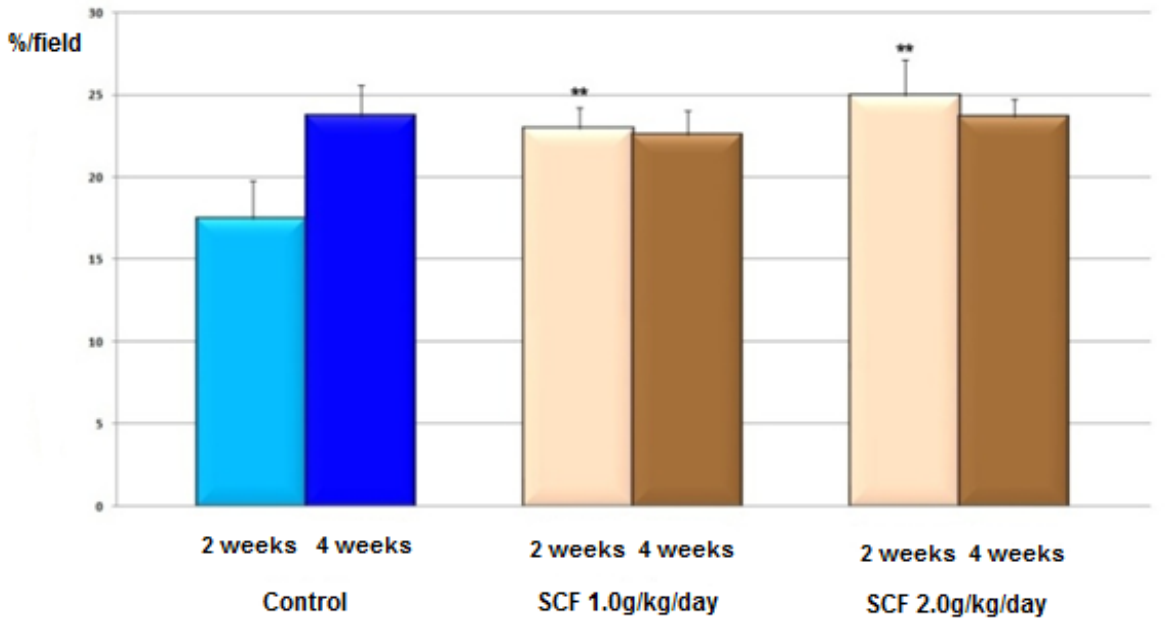

FIGURE 5 - Tissue content of sulfomucins in the control group and SCF1 (SCF $1.0 \mathrm{~g} / \mathrm{kg} /$ day) and SCF2 (2.0 g/kg/day) groups, which were subjected to daily intervention with SCF for 2 and 4 weeks. ${ }^{* *}=p<0.01$ (SCF1 $\times$ Control; SCF2 $\times$ Control). Mann-Whitney test.

Figure 6 shows the tissue content of sialomucins found in the segments without fecal stream after intervention with saline and $1.0 \mathrm{~g} / \mathrm{kg} /$ day and $2.0 \mathrm{~g} / \mathrm{kg} / \mathrm{day} \mathrm{SCF}$ in two to four weeks. The results show that intervention with SCF at a concentration of $1.0 \mathrm{~g} / \mathrm{kg} /$ day or
$1.0 \mathrm{~g} / \mathrm{kg} /$ day or $2.0 \mathrm{~g} / \mathrm{kg} /$ day in a colon devoid of the fecal stream significantly increased the content of sulfomucins two and four weeks after irrigation compared with animals in the control group 


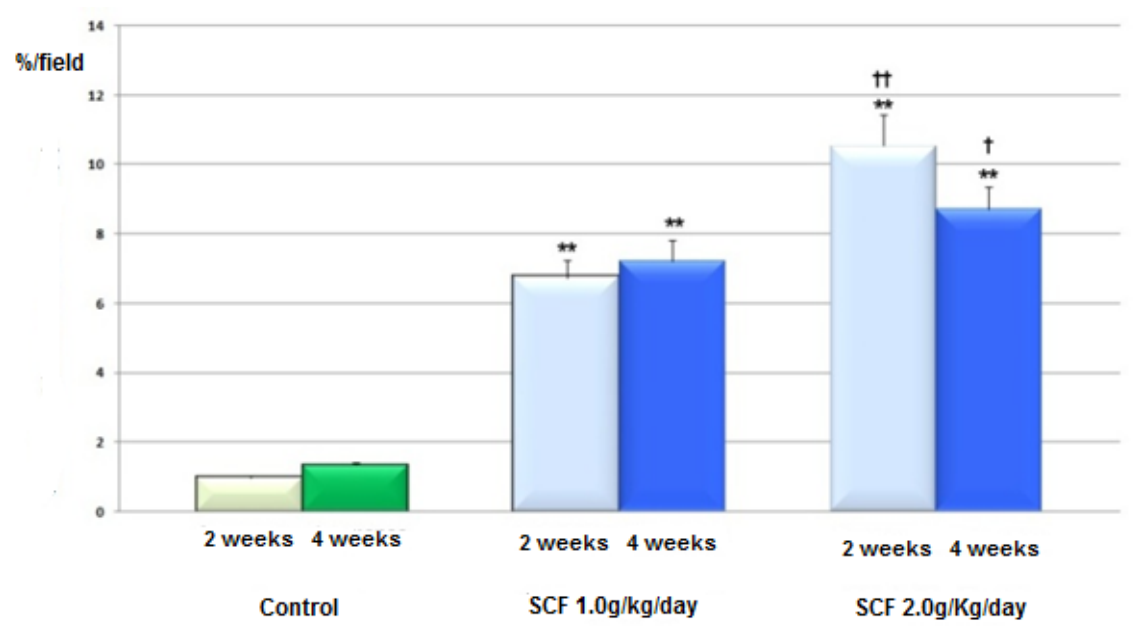

FIGURE 6 - Tissue content of sialomucins in the control group and SCF1 (SCF $1.0 \mathrm{~g} / \mathrm{kg} /$ day) and SCF2 (2.0 g/kg/day) groups, which were subjected to daily intervention with SCF for two and four weeks. ${ }^{*}=\mathrm{p}<0.01$ (SCF1 $\times$ Control; SCF2 $\times$ Control); $\uparrow \uparrow=p<0.01(\mathrm{SCF} 2 \times$ SCF1) after two weeks; $\dagger=\mathrm{p}<0.05$ (SCF2 $\times$ SCF1) after four weeks. Mann-Whitney test.

Table 1 shows the mean values with the corresponding standard error of the variation in the tissue content of total acidic mucins, sulfomucins, and sialomucin in animals subjected to intervention with saline, SCF $1.0 \mathrm{~g} / \mathrm{kg} /$ day and $2.0 \mathrm{~g} / \mathrm{kg} / \mathrm{day}$ according to the intervention time (two or four weeks).

TABLE 1 - Variation of the tissue content of acidic mucin, sulfomucin and sialomucin in animals subjected to intervention with saline, SCF $1.0 \mathrm{~g} / \mathrm{kg} /$ day and SCF $2.0 \mathrm{~g} / \mathrm{kg} /$ day and after two and four weeks.

\begin{tabular}{lccc}
\hline & \multicolumn{3}{c}{ Mean \pm Standard error } \\
\cline { 2 - 4 } Total acidic mucins & $\mathbf{2}$ weeks & 4 weeks & $\mathbf{p}$ \\
Saline & $15.91 \pm 0.86$ & $15.53 \pm 1.00$ & NS \\
SCF1 & $20.36 \pm 0.63$ & $21.33 \pm 0.91$ & NS \\
SCF2 & $28.99 \pm 1.30$ & $29.06 \pm 1.65$ & NS
\end{tabular}

\section{Sulfomucins}

$\begin{array}{lllc}\text { Saline } & 17.46 \pm 2.30 & 23.68 \pm 1.90 & <0.05^{*} \\ \text { SCF1 } & 22.93 \pm 1.93 & 22.57 \pm 1.70 & \text { NS } \\ \text { SCF2 } & 24.95 \pm 2.20 & 23.65 \pm 1.00 & \text { NS }\end{array}$

\begin{tabular}{lccc} 
Sialomucins & & & \\
Saline & $0.97 \pm 0.04$ & $1.32 \pm 0.07$ & NS \\
SCF1 & $6.74 \pm 0.65$ & $7.19 \pm 0.63$ & NS \\
SCF2 & $10.53 \pm 0.81$ & $8.72 \pm 0.70$ & $<0.05^{*}$ \\
\hline
\end{tabular}

$\mathrm{NS}=$ not significant; $*=$ significant $(\mathrm{p} \leq 0.05)$ ANOVA.

\section{Discussion}

SCF is a cytoprotective drug that has been used for decades to treat inflammation of the esophagus, stomach and duodenum, and its cytoprotective action in the gastrointestinal epithelium occurs by different mechanisms ${ }^{17,28,29}$. SCF increases the thickness of the layer of mucus that coats the gastrointestinal mucosa, thereby increasing blood flow to the mucosa, preserving cell viability, and stimulating the production of prostaglandins and endogenous growth factors related to tissue repair ${ }^{28}$. Therefore, it is likely that the SCF has a dual mechanism of action, which is related to the direct interaction of the substance or its components with the surface of injured tissues and, in part, by stimulating the effects of tissue repair ${ }^{28}$.

The increased production of mucins from goblet cells induced by SCF assists in the protection afforded by the mucus layer that covers the intestinal mucosa against aggression by different biological, physical or chemical agents in the intestinal lumen. In contact with epithelial ulceration of the gastrointestinal mucosa, SCF clings tightly to albumin and fibrinogen in the deep ulcer surface, thus forming a stable and insoluble complex that covers and protects the ulceration and functioning as a true mechanical barrier. Moreover, SCF accelerates tissue repair by stimulating the migration of fibroblasts to the site where there is erosion of the gastrointestinal mucosa ${ }^{28,29}$. These two effects are related to the ability of the substance to stimulate mucin production, PGE2 and EGF ${ }^{30}$. The increase in PGE2 production, the principal metabolite of the COX-1 and COX-2, can regulate the local angiogenesis, survival and motility of epithelial cells, and this effect is dose-dependent ${ }^{30}$. A published study showed that SCF significantly increases the production of TGF- $\alpha$ and that the association of SCF with TGF- $\alpha$ can stimulate cell proliferation, promoting mucosal healing ${ }^{31}$. 
Slomiany et al. ${ }^{19}$, evaluated the influence of the administration of SCF on the content, composition and physical properties of mucus overlying the gastric mucosa. SCF could increase the thickness of the mucus layer by $8 \%$ and increase its viscosity 1.9-fold. When analyzing the production of acidic mucins, there was a significant increase in the production, with an increase of $63 \%$ and $81 \%$ in the sulfomucins and sialomucins, respectively ${ }^{19}$. These results suggest that the therapeutic effects of SCF are also related to their ability to increase the content of acidic mucin present in the mucus layer that covers the gastrointestinal tract ${ }^{19,33}$. Among the different mechanisms of action, studies have shown that SCF has remarkable antioxidant action by inhibiting the production of superoxide radicals ${ }^{33,34}$. Laudano et al. ${ }^{34}$, exposed the gastrointestinal mucosa of rats to $\mathrm{H}_{2} \mathrm{O}_{2}$, which potently induces the formation of ROS, and found that SCF has antioxidant effects, protecting the mucosa not only by the presence of aluminum sulfate but also by leading to an increased synthesis of mucins and endogenous prostaglandins.

Most authors believe that the pathogenesis of DC is related to a deficiency in the supply of SCFAs to the mucosa of the colon or rectal segments that lack a fecal stream ${ }^{35,36}$. This possibility is supported by the previous studies reporting that when the supply of SCFAs is deficient, the cells of the colon mucosa lack intestinal transit, which is related to the development of DC, whereas the restoration of the fecal stream or irrigation of the excluded segments with AGCC improves the symptoms and decreases the endoscopic and histological findings in the disease ${ }^{12}$. Despite the important role of maintaining the supply of SCFAs to prevent the development of DC, the molecular mechanisms that cause epithelial lesions have only recently begun to be understood ${ }^{9}$. Experimental studies have shown that the epithelial lesions found in the models of DC are related to the tissue oxidative stress that results from the increased production of ROS by colonic mucosa that is devoid of a fecal stream, a location that is known to be deficient in antioxidant enzyme systems ${ }^{37,38}$. ROS are produced in excess by colonic mucosa without intestinal transit. The increased production of superoxide radicals, hydroxyl and hypochlorous acid, which cause oxidative stress, can damage the various defense systems of the colonic mucosa $\mathrm{a}^{39}$. The damage to these defense systems enables the migration of antigens and bacteria in the intestinal lumen to the intima of sterile layers of the colon wall, thus triggering the inflammatory process found in $\mathrm{DC}^{5,6,9}$. An experimental study showed that it is possible to trigger the onset of epithelial lesions such as those found in the DC by applying enemas with hydrogen peroxide, a potent donor of $\operatorname{ROS}^{15}$. The possibility that ROS may trigger the onset of DC gained more support after studies demonstrated that the application of enemas with antioxidants, such as 5-ASA and $\mathrm{N}$-acetylcysteine, to the excluded colon is effective in controlling the disease ${ }^{11,14,36}$.

The tissue expression and content of the mucins in the excluded colon in humans or experimental models with DC has rarely been studied ${ }^{1,5,6}$. The results from these studies demonstrate that transit modifies the tissue content of neutral and acidic mucin present on the colonic mucosa glands. It is possible that the oxidative stress resulting from intestinal exclusion is the molecular mechanism responsible for the damage to the mucus layer. Nonose et $a l .{ }^{5}$, measured the content of neutral and acidic mucins in the colonic glands in an experimental model of DC and found a reduction in the tissue content of neutral and acidic mucins in the segments without fecal stream. Subsequently, the same group, measuring only acidic mucin subtypes (sulfomucins and sialomucins) found a reduction in the mucins, mainly at the expense of sialomucin ${ }^{6}$. The authors drew attention to the possibility that the reduction in the tissue content of acidic mucins could be related to production of higher levels of ROS in the excluded colon ${ }^{5,6}$. Corroborating this evidence, experimental studies have shown that the preventive application of natural substances, such as the aqueous extract of Ilex paraguariensis or synthetic as n-acetylcysteine and 5-ASA, which are potent antioxidants, reduced the levels of oxidative stress and protected the mucosa that lacked a fecal stream against the deleterious effects of $\operatorname{ROS}^{10-14}$.

It seems obvious that a substance that stimulates the production of mucus by the colonic epithelium and possesses antioxidant activity may also be useful for treating DC. However, one study evaluated the effects of SCF application in an experimental model of DC. The results of this study showed that application of enemas with increasing concentrations of SCF in the excluded colon reduced the loss of epithelial colonic mucosa, decreased mucosal ulcers, impaired the formation of abscesses in the colon crypts and reduced mucosal inflammatory infiltrate ${ }^{40}$. Despite this evidence, no clinical or experimental studies have evaluated the effects of SCF on the synthesis of sulfomucins and sialomucins by cells of the colonic mucosa without fecal stream. Similar to that described above, the results of this study show that the daily use of daily enemas with SCF in the excluded colon transit reduces inflammation of the colon mucosa. This effect was directly related to the concentration and duration of the intervention. Animals subjected to the intervention with the highest concentration (SCF $2.0 \mathrm{~g} / \mathrm{kg} /$ day) and for a longer period of time (4 weeks) showed significant reduction in the inflammatory score, confirming the results of a previous study ${ }^{40}$. We conducted an intervention for a maximum period of four weeks because this 
time period was used in most previous studies ${ }^{10,11,14,15,40}$. However, the inflammatory process may worsen with time. Further studies evaluating the effects of SCF in improved tissue inflammation that also adopt a longer exclusion period are still needed to confirm whether the use of the drug for longer periods maintains a sustained clinical response. Authors who used SCF in patients with RP and DII showed that the effects were more evident with an increasing time of application ${ }^{21-25}$.

The present study demonstrated that the application of enemas containing SCF, independent of the applied concentration, increased the content of acid mucin in the glands of the colon that lacked a fecal stream. Compared with the control group, the increase in the production of acid mucins was independent of the concentration. The increased content of acidic mucins was directly related to the dose used; the animals that received $2.0 \mathrm{~g} / \mathrm{kg} /$ day had a tissue mucin acid content that was significantly higher than those irrigated with a lower concentration. There are several possible explanations for the action of SCF in the colonic mucosa that lacks a fecal stream. It is possible that the preventive application of the substance into a gelatinous layer on the colonic mucosa impairs the contact and penetration of antigens and bacteria in sterile and deeper layers of the intestinal wall, slowing the colonic lumen-derived aggression. However, it is worth remembering that although bacteria, antigens, and chemicals are still present in the excluded colon, it is likely that the levels of these aggressive agents are lower due to fecal exclusion. SCF might provide an antimicrobial effect in the colon, thus reducing the bacterial population and possibility of invasion from other layers of the colon wall and, therefore, reducing the inflammatory process. We are currently evaluating the bacterial flora in the excluded colon that underwent intervention with SCF to evaluate whether the substance has antimicrobial action. Because SCF stimulates the production of PGE2 and increases local blood flow, it is possible that the increased production of acid mucins may be related to the properties of the substance. It is worth remembering that although we found increased tissue levels of sulfomucins and sialomucins in the animals treated with SCF, this increase primarily occurred at the expense of sialomucins, which is the subtype of mucin that has the greatest reduction in the mucosa of the colon lacking a fecal stream $^{6}$. It has been demonstrated that SCF primarily stimulates the production of mucins rich that are in sialic acid ${ }^{19}$. Because the acidic mucins are found in the germ portions of the cramping glands, it is possible that the SCF protection of the colonic mucosa to decrease the need for cellular replication stabilizes the yield of sialomucin. Studies evaluating the content of PGE2, EGF and vascular endothelial growth factor in animals undergoing intestinal intervention with SCF derivation are still needed to confirm this possibility.

SCF has antioxidant activity, and the intestinal bypass significantly increases the production of $\operatorname{ROS}^{9,33}$. As demonstrated with other substances that possess antioxidant activity (5-ASA, n-acetylcysteine and aqueous extract of Ilex paraguariensis), it is also possible that the SCF has the same antioxidant effects on excluded sigmoid traffic mucosa, preventing epithelial assault, neutrophil infiltration and apoptosis of cells producing mucin ${ }^{10,11,14}$. In an unpublished study in which we measured the levels of oxidative tissue stress by measuring malondialdehyde, SCF intervention reduced the levels of lipid peroxidation (oxidative stress) and the presence of myeloperoxidase. It is noteworthy that these effects were related to the expression and content of different types and subtypes of acid mucins.

As noted, all of these questions merit further study. There are still questions about the mechanisms of action of SCF in the excluded colon. Nevertheless, we found that the application of the substance enhances the inflammatory process and increases the production of acid mucins in models of $\mathrm{DC}^{5}$. Ultimately, these results suggest that the application of enemas with SCF could become a valid strategy for treating DC in patients with a stoma.

\section{Conclusion}

The daily application of enemas containing sucralfate increases the tissue content of sulfomucins and sialomucins and reduces the inflammatory changes found in experimental diversion colitis.

\section{References}

1. Keli E, Bouchoucha M, Devroede G, Carnot F, Ohrant T, Cugnenc $\mathrm{PH}$. Diversion-related experimental colitis in rats. Dis Colon Rectum. 1997 Feb;40(2):222-8. PMID: 9075761.

2. Deplancke B, Gaskins HR. Microbial modulation of innate defense: goblet-cells and the intestinal mucus layer. Am J Clin Nutr. 2001 Jun;73(6):1131S-41S. PMID: 11393191.

3. Gaudier E, Rival M, Buisine M, Robineau I, Hoebler C. Butyrate enemas upregulate Muc genes expression but decrease adherent mucus thickness in mice colon. Physiol Res. 2009;58(1):111-9. PMID: 18198997.

4. Finnie IA, Dwarakanath AS, Taylor BA, Rhodes JM. Colonic mucins synthesis is increased by sodium butyrate. Gut. 1995 Jan;36(1):939. PMID: 7890244.

5. Nonose R, Spadari APP, Priolli D, Máximo FR, Pereira JA, Martinez CAR. Tissue quantification of neutral and acid mucins in the mucosa of the colon with and without fecal stream in rats. Acta Cir Bras. 2009 Jul-Ago;24(4):267-75. doi: 10.1590/S0102-86502009000400005.

6. Martinez CAR, Nonose R, Spadari APP, Máximo FR, Priolli DG, Pereira JA, Margarido NF. Quantification by computerized morphometry of tissue levels of sulfomucins and sialomucins in 
diversion colitis in rats. Acta Cir Bras. 2010 Jun;25(3):231-40. doi: 10.1590/S0102-86502010000300004.

7. Habib NA, Dawson PM, Krausz T, Blount MA, Kersten D, Wood CB. A study of histochemical changes in mucus from patients with ulcerative colitis, Crohn's disease, and diverticular disease of the colon. Dis Colon Rectum. 1986 Jan;29(1):15-7. PMID: 3940799.

8. Gaudier E, Forestier L, Gouyer V, Huet G, Julien R, Hoebler C. Butyrate regulation of glycosylation-related gene expression: evidence for galectin-1 upregulation in human intestinal epithelial goblet cells. Biochem Biophys Res Commun. 2004;325:1044-51. PMID: 15541394.

9. Martinez CAR, Ribeiro ML, Gambero A, Miranda DDC, Pereira JA, Nadal SR. The importance of oxygen free radicals in the etiopathogenesis of diversion colitis in rats. Acta Cir Bras. 2010 Oct;25(5):387-95. doi: 10.1590/S0102-86502010000500002.

10. Cunha FL, Silva CMG, Almeida MG, Lameiro TMM, Marques LHS, Margarido NF, Martinez CA. Reduction in oxidative stress levels in the colonic mucosa without fecal stream after the application of enemas containing aqueous Ilex paraguariensis extract. Acta Cir Bras. 2011 Aug;26(4):289-96. doi: 10.1590/S010286502011000400008 .

11. Almeida $\mathrm{MG}$, Pereira JA, Silva CMG, Cunha FL, Marques LHS, Lameiro TMM, Martinez CAR. Evaluation of topical n-acetylcysteine in diversion colitis. J Coloproctol. (Rio J). 2012 jul./set.;32(3):223-31. doi: 10.1590/S2237-93632012000300004.

12. Nassri CGG, Nassri AB, Favero E, Rotta CM, Martinez CAR, Margarido NF. Influência da irrigação de soluções nutricionais no colo excluso de trânsito intestinal: estudo experimental em ratos. Rev Bras Coloproctol. 2008 jul./set.;28(3):306-14. doi: 10.1590/ S0101-98802008000300006.

13. Pacheco RG, Esposito CC, Müller LC, Castelo-Branco MT, Quintella LP, Chagas VL, de Souza HS, Schanaider A. Use of butyrate or glutamine in enema solution reduces inflammation and fibrosis in experimental diversion colitis. World J Gastroenterol. 2012 Aug 28;18(32):4278-87. doi: 10.3748/wjg.v18.i32.4278.

14. Caltabiano C, Máximo FR, Spadari AP, da Conceição Miranda DD, Serra MM, Ribeiro ML, Martinez CA. 5-aminosalicylic acid (5-ASA) can reduce levels of oxidative DNA damage in cells of colonic mucosa with and without fecal stream. Dig Dis Sci. 2011 Apr;56(4):1037-46. doi: 10.1007/s10620-010-1378-z.

15. Marques LHS, Silva CMG, Lameiro TMM, Almeida MG, Cunha FL, Pereira JA, Martinez CAR. Avaliação dos níveis de peroxidação lipídica em células da mucosa cólica após aplicação de enemas com peróxido de hidrogênio: estudo experimental em ratos. Rev Bras Coloproctol. 2010 Jul./Set.;30(3):272-80. doi: 10.1590/S010198802010000300002.

16. Volkin DB, Verticelli AM, Marfia KE, Burke CJ, Mach H, Middaugh CR. Sucralfate and soluble sucrose octasulfate bind and stabilize acidic fibroblast growth factor. Biochim Biophys Acta.1993 Nov 10;1203(1):18-26. PMID: 7692970.

17. Szabo $\mathrm{S}$. The mode of action of sucralfate: The $1 \times 1 \times 1$ mechanism of action. Scand J Gastroenterol. 1991;185(Suppl):7-12. PMID: 1957124.

18. Masuelli L, Tumino G, Turriziani M, Modesti A, Bei R. Topical use of sucralfate in epithelial wound healing: clinical evidence and molecular mechanisms of action. Recent Pat Inflamm Allergy Drug Discov. 2010 Jan;4(1):25-36. PMID: 19832693.

19. Slomiany BL, Piotrowski J, Okazaki K, Grzelinska E, Slomiany A. Nature of the enhancement of the protective qualities of gastric mucus by sucralfate. Digestion. 1989;44(4):222-31. PMID: 2483693

20. Wada K, Kamisaki Y, Kitano M, Kishimoto Y, Nakamoto K, Itoh T. Effects of sucralfate on acute gastric mucosal injury and gastric ulcer induced by ischemia-reperfusion in rats. Pharmacology.1997 Feb;54(2):57-63. PMID: 9088038.

21. Kochhar R, Mehta SK, Aggarwal R, Dhar A, Patel F. Sucralfate enema in ulcerative rectosigmoid lesions. Dis Colon Rectum. 1990 Jan;33(1):49-51. PMID: 2295277.

22. Wright JP, Winter TA, Candy S, Marks IS. Sucralfate and methylprednisolone enemas in active ulcerative colitis: a prospective, single-blind study. Dig Dis Sci. 1999 Sep;44(9):1899901. PMID: 10505732.

23. Matsuu-Matsuyama M, Shichijo K, Okaichi K, Ishii K, Wen CY, Fukuda E, Nakayama T, Nakashima M, Okumura Y, Sekine I. Sucralfate protects intestinal epithelial cells from rediationinduced apoptosis in rats. J Radiat Res. 2006 Mar;47(1):1-8. PMID: 16571913.

24. Denton AS, Andreyev HJN, Forbes A, Maher EJ. Systematic review for non-surgical interventions for the management of late radiation proctitis. Br J Cancer. 2002 Jul 15;87(2):134-43. PMID: 12107832.

25. Henson C. Chronic radiation proctitis: issues surrounding delayed bowel dysfunction post-pelvic radiotherapy and an update on medical treatment. Ther Adv Gastroenterol. 2010 Nov;3(10):35965. doi: 10.1177/1756283X10371558.

26. Mendenhall WM, McKibben BT, Hoppe BS, Nichols RC, Henderson RH, Mendenhall NP. Management of radiation proctitis. Am J Clin Oncol. 2013 Oct;37(5):517-23. doi: 10.1097/ COC.0b013e318271b1aa.

27. Dehghani SM, Malekpour A, Haghighat M. Solitary rectal ulcer syndrome in children: a literature review. World J Gastroenterol. 2012 Dec 7;18(45):6541-5. doi: 10.3748/wjg.v18.i45.6541.

28. Rees WD. Mechanisms of gastroduodenal protection by sucralfate. Am J Med. 1991 Aug 8;91(2A):58S-63S. PMID: 1715673.

29. Robert A, Nezamis JE, Lancaster C, Hanchar AJ. Cytoprotection by prostaglandins in rats. Prevention of gastric necrosis produced by alcohol, $\mathrm{HCl}, \mathrm{NaOH}$, hypertonic $\mathrm{NaCl}$, and thermal injury. Gastroenterology.1979 Sep;77(3):433-43. PMID: 456839.

30. Slomiany BL, Murty VL, Piotrowski E, Morita M, Piotrowski J, Slomiany A. Activation of arachidonoyl phospholipase A2 in prostaglandin-mediated action of sucralfate. Gen Pharmacol. 1994 Mar;25(2):261-6. PMID: 8026724.

3. Louw JA, Modlin IM, Tang L, Young GO, Lucke W, Marks IN. Changes in mucosal levels of transforming growth factor-alpha from the oxyntic region and ulcer site during duodenal ulcer healing with ranitidine or sucralfate. J Int Med Res. 1998 Mar-Apr;26(2):82-6. PMID: 9602986.

32. Scheiman JM, Kraus ER, Yoshimura K, Boland CR. Effect of sucralfate on components of mucosal barrier produced by cultured canine epithelial cells in vitro. Dig Dis Sci. 1992 Dec;37(7):1853-9. PMID: 1618052.

33. al-Swayeh OA, al-Humayyd MS, Mustafa AA, al-Tuwaijri AS, alRashed RS, Ali AT. Sucralfate attenuates gastric mucosal lesions and increased vascular permeability induced by ischaemia and reperfusion in rats. J Gastroenterol Hepatol. 1997 Jul;12(7):481-9. PMID: 9257237.

34. Laudanno OM, Bedini OA, Cesolari JA, San Miguel P. Evidence of anti-oxidant role of sucralfate in gastric mucosal protection. Ital J Gastroenterol. 1990 Feb;22(1):19-21. PMID: 2131922.

35. Villanacci V, Talbot IC, Rossi E, Bassotti G. Ischaemia: a pathogenetic clue in diversion colitis? Colorectal Dis. 2007 Sep;9(7):601-5. PMID: 17824976.

36. Wong JM, de Souza R, Kendall CW, Emam A, Jenkins DJ. Colonic health: fermentation and short chain fatty acids. J Clin Gastroenterol. 2006 Mar;40(3):235-43. PMID: 16633129.

37. Liu Q, Shimoyama T, Suzuki K, Umeda T, Nakaji S, Sugawara K. Effect of sodium butyrate on reactive oxygen species generation by 
human neutrophils. Scand J Gastroenterol. 2001 Jul;36(7):744-50. PMID: 11444474.

38. Longatti TS, Acedo SC, de Oliveira CC, Miranda DD, Priolli DG, Ribeiro ML, Gambero A, Martinez CA. Inflammatory alterations in excluded colon in rats - a comparison with chemically-induced colitis. Scand J Gastroenterol. 2010 Mar;45(3):315-24. doi: 10.3109/00365520903471572.

39. Martinez CA, de Almeida MG, da Silva CM, Ribeiro ML, da Cunha FL, Rodrigues MR, Sato DT, Pereira JA. Enemas with $\mathrm{N}$-acetylcysteine can reduce the level of oxidative damage in cells of the colonic mucosa diverted from the faecal stream. Dig Dis Sci. 2013 Dec;58(12):3452-9. doi: 10.1007/s10620-013-2768-9.

40. Pereira JA, Rodrigues MR, Sato DT, Silveira Junior PP, Dias AM, Silva CG, Martinez CAR. Evaluation of sucralfate enema in experimental diversion colitis. J Coloproctol. 2013 NovDez;33(4):182-90. doi: 10.1016/j.jcol.2013.08.005.

\section{Correspondence:}

Carlos Augusto Real Martinez

Rua Rui Barbosa, 255/32

09190-370 São Paulo - SP Brasil

Tel.: (55 11)4438-9203

carmartinez@uol.com.br

Received: Jan 14, 2015

Review: Mar 12, 2015

Accepted: Apr 15, 2015

Conflict of interest: none

Financial source: Sao Paulo Research Foundation (FAPESP). Project $n^{\circ}$. 2010/12492-7.

${ }^{1}$ Research performed at Laboratory of Medical Investigation, Medical School, Sao Francisco University (USF), Bragança Paulista-SP, Brazil. Part of Master degree thesis, Postgraduate Program in Health Sciences, USF. Tutor: Carlos Augusto Real Martinez. 